\title{
Engineering Plant Virus Resistance: Gene Silencing to Genome Editing
}

\author{
Biswajit Lenka $^{1 *}$, Satya Narayan Satapathy ${ }^{2}$ and Manoranjan Senapati ${ }^{3}$ \\ ${ }^{1}$ Department of Genetics and Plant Breeding, Junagadh Agricultural University, Junagadh, \\ Gujarat-362001, India \\ ${ }^{2}$ Department of Entomology, Institute of Agricultural Sciences, Siksha 'O' Anusandhan \\ (Deemed to be University), Bhubaneswar, Odisha-751029, India \\ ${ }^{3}$ Division of Genetics, ICAR- IARI, New Delhi-110012, India \\ *Corresponding author
}

\section{Keywords}

Plant virus, RNA

silencing,

CRISPR/Cas9,

Genome editing,

Antiviral breeding

Article Info

Accepted:

24 September 2020

Available Online:

10 October 2020

\begin{abstract}
A B S T R A C T
How dreadful a virus may be - this has been well understood across the globe during the COVID-19 pandemic. Viruses pose a serious threat not only to mankind but also to agriculture by infecting several economically important crops such as rice, wheat, corn, cotton, and vegetables. Conventional methods will not be able to control these quickly evolving and emerging plant viruses. Present-day genome-editing techniques have emerged as promising tools to introduce desirable traits in target crop plant. The two major antiviral strategies, RNA silencing and genome editing have been vividly discussed in this review article. RNA silencing strategy has been utilized in antiviral breeding for more than three decades. Many crops engineered to stably express small RNAs targeting various viruses have been approved for commercial release. Among these technologies, the CRISPR/Cas9 system has gained more popularity by virtue of its simplicity, efficiency and reproducibility. CRISPR/Cas9 have been exploited to engineer plant virus resistance, either by directly targeting and cleaving the viral genome, or by modifying the host plant genome to introduce viral immunity. Here, we describe the biology of the CRISPR/Cas9 system and plant viruses, and how this genome engineering tool has been used to target the devastating plant viruses.
\end{abstract}

\section{Introduction}

The global population has increased by over $25 \%$ in the last two decades and is estimated to increase from 7.7 billion in 2019 to around 10 billion by 2050. Supplying adequate amount of healthy and nutritious food to the burgeoning global population is the biggest challenge at present. Nevertheless, the rate of grain production does not seem to have kept pace with population growth across the globe. In addition to confined cultivable land and water resources, the global food production is also limited by insect pests and disease causing pathogens. The yield of crop plants is threatened by insect pests which cause yield loss of $20-40 \%$, while bacterial and fungal pathogens reduce crop yields by about $15 \%$ and viruses reduce yield by 3-7\% (Oerke and Dehne, 2004). Yield losses due to plant 
viruses are not so great compared to that of bacterial and fungal diseases, but the outbreak of viral diseases may lead to several problems. Economic losses due to plant virus infection may reach up to 60-80 billion dollar in a year. It is so because the bacterial and fungal pathogens can be controlled by chemical pesticides whereas the same can't be done with viruses. Pesticide application and use of natural predators against the vectors or using physical barriers are few control measures for viruses which can be readily adopted at present. Development of virusresistant varieties is the most effective way to reduce yield losses caused by viral diseases. Conventional breeding plays a vital role in crop improvement for viral resistance but usually time-consuming and laborious process. The emergence of genetic engineering, which directly alters the organism's genetic information using modern biotechnology, has significantly accelerated the process and efficiency of breeding (Christou, 2013). Increasing knowledge about the molecular mechanism of plant-virus interactions and biotechnological advancement provides new opportunities for engineering plant resistance to viruses. (Mahas and Mahfouz, 2018; Yin and Qiu, 2019).

\section{Plant Viruses}

Global agriculture is threatened by both abiotic (cold, drought, salinity, heat etc.) and biotic stresses (bacteria, fungi, viruses, insects, nematodes etc.). Phytopathogenic viruses or plant viruses cause about $10-15 \%$ reduction in global crop yields each year (Mahy and van Regenmortel, 2009). Thus, improving host plant resistance against plant viruses can mitigate these losses by protecting a significant proportion of food crops. The mode of infection and transmission of viruses provide several potential targets for controlling plant viruses; however their huge diversity and rapid evolution make such control measures difficult (Hanley-Bowdoin et al., 2013). Most of the plant viruses are transmitted by vectors that feed on plants such as insects (whiteflies, plant hoppers, jassids, thrips etc.), mites, nematodes and plasmodiophores (Whitfield et al., 2015). Prominent symptoms of virus-infected plants are usually those appearing on the leaves, but some may cause symptoms on the stem, fruit, and roots. The most common types of plant symptoms produced by virus infections are mosaics and ring spots. The most common viral symptoms are mosaics and ring spots on leaves, leaf roll, stunting and dwarfing of plants, leaf yellowing, streak, pox, pitting of stem etc. (Ghoshal and Sanfacon, 2015). Plant viruses are classified into six major groups based on their genomes: double-stranded DNA (dsDNA) viruses, single-stranded DNA (ssDNA) viruses, reverse-transcribing viruses, double-stranded RNA (dsRNA) viruses, negative sense single-stranded RNA (ssRNA) viruses, and positive sense single- stranded RNA (ssRNA) viruses (Roossinck et al., 2015).

\section{Virus Control Strategies}

Traditional virus control measures include vector management by synthetic pesticides, triggering the activity of natural predators, or using physical barriers such as reflective mulches and UV-absorbing sheets (Legg et al., 2014). Cultural practices like early sowing, weed management, fallow period, virus free planting material and discarding infected plants from field have also been adopted for control of viral diseases. Exploiting genetic resistance in crop plants in this regard by boosting plant cellular immunity against phytopathogenic viruses is comparatively most effective strategy as the conventional methods are labour-intensive, time consuming and often ineffective (Whitham and Hajimorad, 2016). Thus, the 
most productive approach for disease control will likely be the development of virus or vector resistant plant genotypes in combination with other control measures. Therefore, ongoing research is mainly focused on the understanding of plant cellular mechanisms for virus and vector resistance (Mandadi and Scholthof, 2013). Several such mechanisms have been discovered and artificially introduced or enhanced within plants to successfully demonstrate engineered virus resistance (Sahu and Prasad, 2015).

\section{Genome Engineering}

Genome engineering has come up as a novel tool to genetically improve crop plants, by introducing desirable traits through the sitespecific modification of the genome (Sovova et al., 2016). Besides its ease and reproducibility, one fascinating aspect of such technologies is that once the desired genome modifications have been made, the transgenes can be crossed out from the improved variety, thus evading public and political worries around the utilization of incessant transgenes in food crops (Kanchiswamy, 2016). Here we elaborate use of three major classes of SSNs such as zinc finger nucleases (ZFNs), transcription activator-like effector nucleases (TALENs), and clustered regularly interspaced palindromic repeats/CRISPRassociated 9 (CRISPR/Cas9) in engineering plant virus resistance (Figure 1). Genome engineering makes use of site specific enzymes (SSNs) that can bind and cleave a specific nucleic acid sequence by introducing double stranded breaks (DSBs). These DSBs thus created can be repaired either through non-homologous end joining (NHEJ) or homologous recombination. Repair of DSBs through NHEJ often leads to the formation of small insertions or deletions (INDELs) that can lead to loss-of-function mutation. Repair through homologous recombination is relatively complex as it needs the simultaneous delivery of a DNA repair template that carries the desired modification to be incorporated into the repaired locus (Stella and Montoya, 2016).

\section{Engineering RNA silencing-based resistance}

RNA silencing, also referred to as RNA interference (RNAi), is activated by the presence of double-stranded RNA molecules (dsRNAs) and induces gene expression inhibition or suppression in a nucleotide sequence-specific manner. In plants, various key protein families are involved in RNA silencing, including dicer-like (DCL), argonautes (AGO) etc. DCL proteins, a type III RNase, process dsRNA or miRNA precursors into siRNA or miRNA, respectively, of 20 to $24-n t$ long with a two base overhang at the 3 ' end. These siRNAs or miRNAs are incorporated into the endonuclease AGO proteins to form RNAinduced silencing complex (RISC). RISC bind to target mRNA as directed by its siRNA/miRNA and then silence the expression of target gene by cleaving target RNA and inhibiting the transcription of the target gene (Figure 2).

For the RNA silencing based antiviral defense, the successful introduction of dsRNA to target begomoviruses was first reported for a single common bean transgenic line expressing a siRNA for Rep gene silencing from BGMV (Aragao and Faria, 2009), which was later demonstrated to produce siRNA (Aragao et al., 2013). Similarly, two independently transformed tomato transgenic lines designated to generate siRNA cognate to a Rep gene fragment from TYLCV have been shown to be immune to this begomovirus under field conditions. By now, gene silencing has been successfully exploited to target over 60 species of economically important plant viruses, 
including Banana bunchy top virus (Elayabalan et al., 2013), Papaya ringspot virus (PRSV) (Bau et al., 2003 and Ye and Li, 2010), and Citrus tristeza virus (Soler et al., 2012). Near about 30 crop species have been engineered to stably express small RNAs targeting several viruses, dozens of which have been approved for commercial release in several countries, such as papaya resistant to Papaya ringspot virus (PRSV), squash resistant to Cucumber mosaic virus (CMV) and potato resistant to Potato leaf roll virus (PLRV) or Potato virus Y (PVY).

Several other studies have also demonstrated the potential of RNA silencing to control the infection of plant viruses. Expression of double stranded RNA, which target AV1 and AV2 genes from the Sri Lankan cassava mosaic virus (SLCMV) and $\mathrm{AC} 1 / \mathrm{AC} 2$ or $\mathrm{AC} 1 / \mathrm{AC} 2 / \beta \mathrm{C} 1$ from various species of Chilli leaf curl virus, has been demonstrated to activate post transcriptional gene silencing in transgenic lines (Sharma et al., 2015). Trans-acting small interfering RNA (tasiRNA) targeting AC2 and AC4 of the geminivirus Tomato leaf curl New Delhi virus (ToLCNDV) has also been used to generate resistance in transgenic tomato lines (Singh et al., 2015). Similarly, RNAi constructs homologous to the intergenic region (IR) or targeting the V2 gene from Cotton leaf curl Kokhran virus-Burewala strain (CLCuKoV-Bu) have exhibited resistance in transgenic lines of cotton.

Some other successful applications of the RNA silencing based antiviral breeding were performed in Maize streak virus (MSV) (Shepherd et al., 2007), Maize dwarf mosaic virus (MDMV) (Zhang et al., 2013), Soybean mosaic virus (SMV) (Gao et al., 2015; Wang et al., 2001) and Tomato yellow leaf curl virus (TYLCV) (Antignus et al., 2004; Fuentes et al., 2006). Above cited are few of the many successful instances of RNAi-based engineering plant virus resistance. Nevertheless, these transgenic innovations are not only tedious and costly, but also go through certain guidelines and public acknowledgement issues. To address these constraints and public concerns, several approaches which involve exogenous application of naked dsRNA proved to successfully trigger the RNA silencing pathway against the phtopathogenic viruses (Lau et al., 2014; Kaldis et al., 2018; Namgial et al., 2019; Worrall et al., 2019). One major drawback of this system is its short virus protection window of 5-7 days after application (Mitter et al., 2017).

\section{Engineering ZFN or TALEN-based resistance}

Zinc finger nucleases (ZFNs) and transcription activator-like effector nucleases (TALENs) were the first-generation tools of genome editing technology. These genome editing techniques serve as a new weapon in the arsenal against plant viruses. Both ZFNs and TALENs are chimeric proteins generated by fusing a DNA-binding domain (DBD) to a non-specific cleavage domain of the enzyme FokI. The DBD determines a specific nucleotide recognition in the DNA target and the cleavage domain cleaves DNA to produce the double-strand breaks (DSB) in the targeted site (Zaidi et al., 2017). Zinc finger nucleases are chimeric proteins synthesized by fusing the DNA-binding domain (DBD) of a zinc-finger protein with the DNA cleavage domain of the FokI restriction enzyme (Urnov et al., 2010). FokI restriction enzyme works as a dimer and its catalytic domain cleaves the DNA sequence outside of the recognition site (Bitinaite et al., 1998). ZFN comprises of two monomers that are separated by a spacer sequence of 5-7 bp wherein the catalytic domains of the chimeric proteins cleave each DNA band to produce the DSB (Christian et al., 2010). 
Table.1 Comparison of the strategies used in engineering antiviral plants

\begin{tabular}{|l|l|l|}
\hline Strategies & Advantages & Disadvantages \\
\hline RNA silencing & High efficiency & $\begin{array}{l}\text { Many viruses can encode } \\
\text { VSRs to counter the defense } \\
\text { of RNA silencing }\end{array}$ \\
\hline CRISPR/Cas9 targeting DNA & $\begin{array}{l}\text { The eukaryotic plant } \\
\text { viruses have not evolved to } \\
\text { possess the ability to } \\
\text { counter this immune } \\
\text { defense coming from } \\
\text { might be repaired and escape } \\
\text { the engineered resistance } \\
\text { prokaryote }\end{array}$ \\
\hline Host factors editing & $\begin{array}{l}\text { The targeted RNA is } \\
\text { further degraded and has } \\
\text { less chance to produce } \\
\text { mutant viruses }\end{array}$ & $\begin{array}{l}\text { Off-target effect may affect } \\
\text { the expression of some host } \\
\text { genes, but will not change } \\
\text { the plant genome }\end{array}$ \\
\hline $\begin{array}{l}\text { The gene editing machinery } \\
\text { can be removed by } \\
\text { backcross, so it is able to } \\
\text { engineer virus resistant } \\
\text { plant which is transgenic- } \\
\text { free }\end{array}$ & $\begin{array}{l}\text { Loss-of-function of some } \\
\text { host factors may lead to } \\
\text { lethality or impaired growth }\end{array}$ \\
\hline
\end{tabular}

Fig.1 Three major types of genome engineering platforms: A. Zinc finger nucleases (ZFNs), B. clustered regularly interspaced palindromic repeats/CRISPR-associated 9 (CRISPR/Cas9) and C. transcription activator-like effector nucleases (TALENs)
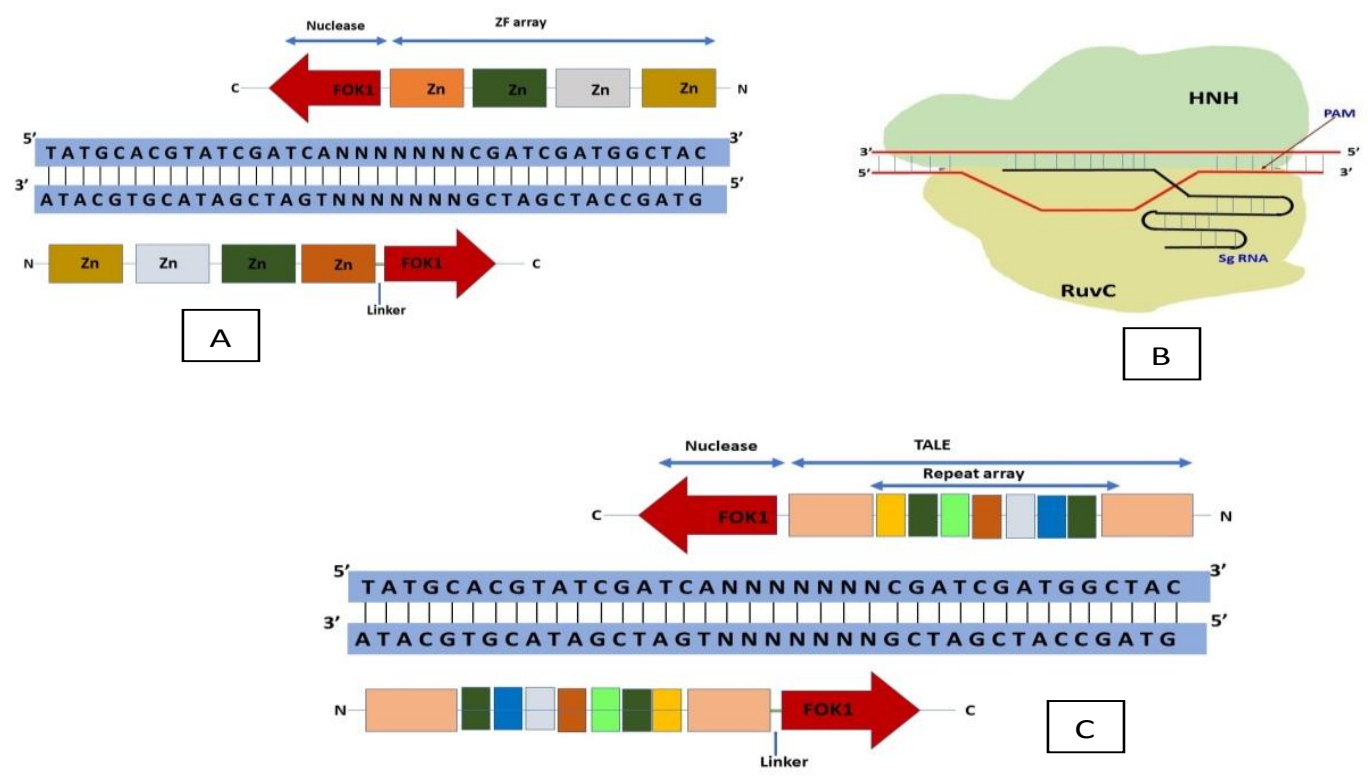
Fig.2 Schematic diagram depicting RNA silencing and CRISPR/Cas strategies to target plant viruses

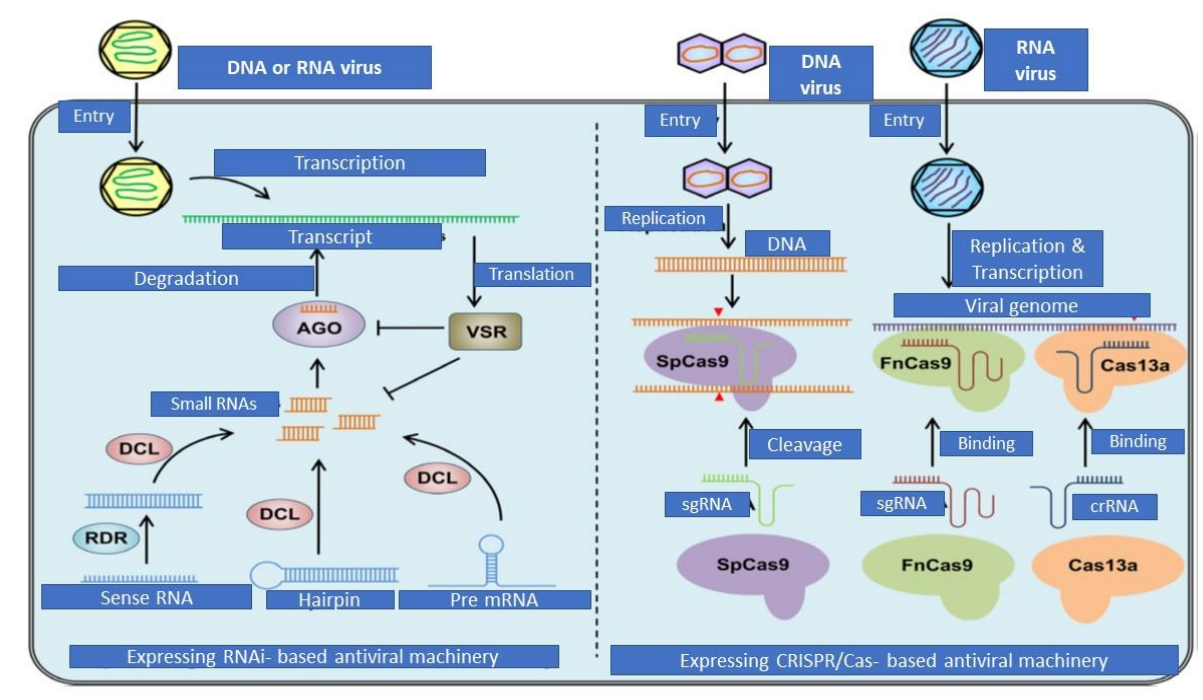

An effective ZFN consist of more than three zinc-finger domains in each DNA-binding module to increase specific DNA recognition (Gaj et al., 2013). An artificial zinc finger protein (AZP) in planta targeting a $19 \mathrm{bp}$ fragment in the intergenic region (IR) of Beet severe curly top virus (BSCTV) was developed by Sera in 2005. In vitro assays have been conducted to predict inhibition of Tomato yellow leaf curl virus (TYLCV) with the help of AZP technology by blocking the Rep binding site of the virus (KoshinoKimura et al., 2009; Mori et al., 2013). Likewise, AZP technology was also harnessed to reduce the replication of Rice tungro bacilliform virus (RTBV) in transgenic Arabidopsis thaliana carrying a zinc finger protein capable of recognizing and blocking promoter sequence of the virus (Ordiz et al., 2010).

TALEN is a fusion of a transcription activator-like effector and the non-specific cleavage domain of the restriction enzyme FokI. Transcription activator-like effectors (TALEs) are nothing but proteins encoded by phytopathogenic bacteria Xanthomonas spp. which are delivered into the host plant cells in order to promote pathogen growth through manipulation of plant processes (Schornack et al., 2013). Once these proteins are delivered into the plant cells they translocate to the nucleus and bind to the target DNA. TALEs are composed of three different domains such as: a) N-terminal secretion and translocation domain, b) central DNA Binding Domain (DBD) and c) C-terminal transcription activation domain (Schornack et al., 2013). The intergenic region (IR) of geminiviruses contains a stem-loop structure which is required for viral replication by an initiator protein (Rep) binding. The transgenic artificial zinc finger protein AZP efficiently binds the IR of Beet severe curly top virus (BSCTV), thus blocking the Rep binding and subsequently suppressing the infection of the virus (Sera, 2005). TALEs, lacking the nuclease domain compared to TALEN, were developed to target conserved motifs among begomoviruses. Tobacco plants expressing the TALEs showed resistance to TbCSV and partial resistance to Tomato leaf curl Yunnan virus (TLCYnV) was partial (Cheng et al., 2015). 
Engineering CRISPR/Cas9 based resistance

ZFNs and TALENs have expeditiously been outstriped by a new emerging genome editing tool in plants popularly known as CRISPR/Cas9 system of genome editing since its advent. The clustered regularly interspaced short palindromic repeats/ CRISPR-associated protein (CRISPR/Cas) system is based on an adaptive immune system that eliminates entry of foreign viral DNA via cleavage in bacteria and archaea (Bhaya et al., 2011). The system comprises an endonuclease Cas protein and a guide RNA (Figure 2). CRISPR/Cas system is a renowned for its simplicity, higher efficiency and affordability compared to preceding tools such as ZFN and TALEN. Numerous efforts are going on to combat human as well as plant viruses using the CRISPR/Cas technique (Price et al., 2016).

The original CRISPR/Cas system from the bacterium Streptococcus pyogenes, used for genome editing with DNA as its target. Therefore, the CRISPR/Cas system was first used to fight geminivirus targeting the viral genomic DNA. Tobacco and Arabidopsis were reported for successful use of CRISPR/Cas9 to generate resistance against geminiviruses. Three groups reported the successful use of CRISPR/Cas9 to generate geminivirus resistance in tobacco and Arabidopsis. Single guide RNAs (sgRNAs) were designed to target the IR, Rep or CP loci, and thereby reduce symptoms of several geminiviruses (Ali et al., 2015; Baltes et al., 2015; Ji et al., 2015). $N$. benthamiana plants expressing the CRISPR/Cas9 machinery exhibited resistance against TYLCV, Beet curly top virus (BCTV), and Merremia mosaic virus (MeMV) (Ali et al., 2015). Virus interference activities in $N$. benthamiana against Bean yellow dwarf virus (BeYDV) and Beet severe curly top virus (BSCTV), by Baltes et al., and $\mathrm{Ji}$ et al., respectively (Baltes et al., 2015; Ji et al., 2015). CRISPR/Cas machinery was effectively used in a recent study in barley and established efficient resistance against Wheat dwarf virus (WDV) (Kis et al., 2019). CRISPR/Cas9 has also been proved to be effective in inhibiting the virulence of Cauliflower mosaic virus (CaMV) in Arabidopsis (Liu et al., 2018).

RNA viruses are comparatively more damaging to agricultural production than DNA viruses. With the advancement of CRISPR/Cas system, variants of Cas protein such as the Cas9 from Francisella novicida (FnCas9) and the Cas13a from Leptotrichia shahii (LshCas13a) or Leptotrichia wadei (LwaCas13a), have been reported to target RNA in vivo (Abudayyeh et al., 2016, 2017; Sampson et al., 2013). FnCas9 and its sgRNA were engineered to target CMV and TMV and virus accumulation was thereby reduced and attenuated disease symptoms were observed in tobacco and Arabidopsis expressing the antiviral system (Zhang et al., 2018). Two different groups successfully used the LshCas13a system system to inhibit potyvirus infection in tobacco and potato (Aman et al., 2018; Zhan et al., 2019), while resistance to RNA viruses in both dicot and monocot plants was established by Zhang et al., 2019 (Figure 2). By using CRISPR/Cas9, knockout of Arabidopsis eIF(iso)4E resulted in resistance to TuMV without affecting the plant growth (Pyott et al., 2016), although these translation initiation factors are important for growth and reproduction.

In conclusion the application of modern biotechnology has huge potential to overcome the limitations of conventional viral resistance breeding. Both RNAi and genome editing technologies are particularly applicable to crops with limited genome sequence information. These technologies do not demand for crossing between different 
genotypes and further selection in the segregating generations. CRISPR/Cas9 system is an effective way to generate virusresistant crops by destroying an essential host factor. Through several generations of backcross and screening, or even using DNAfree delivery of in vitro transcripts of CRISPR/Cas9 by particle bombardment (Liang et al., 2018), virus-resistant crops can be generated that are free from transgenes. Zinc finger nuclease and TALEN approaches are not widely used due to their weaknesses related to affordability, simplicity and efficiency. Especially, with the rapid development of CRISPR technology, there are only a few examples of using these genome editing approaches to generate virusresistant crops. Various biotechnological approaches have their own advantages and disadvantages (Table 1). The full potential of RNAi and CRISPR/Cas systems for engineering resistance against eukaryotic viruses is yet to be exploited. Intensive research is required to improve these systems. However the combination of RNA silencing and CRISPR/Cas strategies has extraordinary potential in antiviral breeding.

\section{References}

Abudayyeh, O. O., Gootenberg, J. S., Essletzbichler, P., Han, S., Joung, J., Belanto, J. J. and Lander, E. S. (2017). RNA targeting with CRISPR-Cas13. Nature, 550(7675), 280-284.

Abudayyeh, O. O., Gootenberg, J. S., Konermann, S., Joung, J., Slaymaker, I. M., Cox, D. B. and Severinov, K. (2016). C2c2 is a single-component programmable RNAguided RNA-targeting CRISPR effector. Science, 353(6299).

Ali, Z., Abulfaraj, A., Idris, A., Ali, S., Tashkandi, M. and Mahfouz, M. M. (2015). CRISPR/Cas9-mediated viral interference in plants. Genome biology, 16(1), 238.

Aman, R., Ali, Z., Butt, H., Mahas, A., Aljedaani, F., Khan, M. Z. and Mahfouz, M. (2018). RNA virus interference via
CRISPR/Cas13a system in plants. Genome biology, 19(1), 1-9.

Antignus, Y., Vunsh, R., Lachman, O., Pearlsman, M., Maslenin, L., Hananya, U. and Rosner, A. (2004). Truncated Rep gene originated from Tomato yellow leaf curl virus-Israel [Mild] confers strain-specific resistance in transgenic tomato. Annals of Applied Biology, 144(1), 39-44.

Aragão, F. J. and Faria, J. C. (2009). First transgenic geminivirus-resistant plant in the field. Nature Biotechnology, 27(12), 1086-1088.

Aragão, F. J., Nogueira, E. O., Tinoco, M. L. P. and Faria, J. C. (2013). Molecular characterization of the first commercial transgenic common bean immune to the Bean golden mosaic virus. Journal of biotechnology, 166(1-2), 42-50.

Baltes, N. J., Hummel, A. W., Konecna, E., Cegan, R., Bruns, A. N., Bisaro, D. M. and Voytas, D. F. (2015). Conferring resistance to geminiviruses with the CRISPR-Cas prokaryotic immune system. Nature Plants, 1(10), 1-4.

Bau, H. J., Cheng, Y. H., Yu, T. A., Yang, J. S. and Yeh, S. D. (2003). Broad-spectrum resistance to different geographic strains of Papaya ringspot virus in coat protein gene transgenic papaya. Phytopathology, 93(1), 112-120.

Bhaya, D., Davison, M. and Barrangou, R. (2011). CRISPR-Cas systems in bacteria and archaea: versatile small RNAs for adaptive defense and regulation. Annual review of genetics, 45, 273-297.

Bitinaite, J., Wah, D. A., Aggarwal, A. K. and Schildkraut, I. (1998). FokI dimerization is required for DNA cleavage. Proceedings of the national academy of sciences, 95(18), 10570-10575.

Cheng, X., Li, F., Cai, J., Chen, W., Zhao, N., Sun, Y., and Wu, X. (2015). Artificial TALE as a convenient protein platform for engineering broad-spectrum resistance to begomoviruses. Viruses, 7(8), 4772-4782.

Christian, M., Cermak, T., Doyle, E. L., Schmidt, C., Zhang, F., Hummel, A. and Voytas, D. F. (2010). Targeting DNA double-strand breaks with TAL effector nucleases. Genetics, 186(2), 757-761. 
Christou, P. (2013). Plant genetic engineering and agricultural biotechnology 1983-2013. Trends in biotechnology, 31(3), 125-127.

Elayabalan, S., Kalaiponmani, K., Subramaniam, S., Selvarajan, R., Panchanathan, R., Muthuvelayoutham, R. and Balasubramanian, P. (2013). Development of Agrobacterium-mediated transformation of highly valued hill banana cultivar Virupakshi (AAB) for resistance to BBTV disease. World Journal of Microbiology and Biotechnology, 29(4), 589-596.

Fuentes, A., Ramos, P. L., Fiallo, E., Callard, D., Sánchez, Y., Peral, R. and Pujol, M. (2006). Intron-hairpin RNA derived from replication associated protein $\mathrm{C} 1$ gene confers immunity to Tomato yellow leaf curl virus infection in transgenic tomato plants. Transgenic Research, 15(3), 291304.

Gaj, T., Gersbach, C. A. and Barbas, C. F. (2013). ZFN, TALEN, and CRISPR/Cas-based methods for genome engineering. Trends in biotechnology, 31(7), 397-405.

Gao, L., Ding, X., Li, K., Liao, W., Zhong, Y., Ren, R. and Zhi, H. (2015). Characterization of Soybean mosaic virus resistance derived from inverted repeatSMV-HC-Pro genes in multiple soybean cultivars. Theoretical and Applied Genetics, 128(8), 1489-1505.

Ghoshal, B. and Sanfaçon, H. (2015). Symptom recovery in virus-infected plants: revisiting the role of RNA silencing mechanisms. Virology, 479, 167-179.

Hanley-Bowdoin, L., Bejarano, E. R., Robertson, D. and Mansoor, S. (2013). Geminiviruses: masters at redirecting and reprogramming plant processes. Nature Reviews Microbiology, 11(11), 777-788.

Ji, X., Zhang, H., Zhang, Y., Wang, Y. and Gao, C. (2015). Establishing a CRISPR-Caslike immune system conferring DNA virus resistance in plants. Nature Plants, 1(10), $1-4$.

Kaldis, A., Berbati, M., Melita, O., Reppa, C., Holeva, M., Otten, P. and Voloudakis, A. (2018). Exogenously applied dsRNA molecules deriving from the Zucchini yellow mosaic virus (ZYMV) genome move systemically and protect cucurbits against ZYMV. Molecular plant pathology, 19(4), 883-895.

Kanchiswamy, C. N. (2016). DNA-free genome editing methods for targeted crop improvement. Plant cell reports, 35(7), 1469-1474.

Kis, A., Hamar, É., Tholt, G., Bán, R. and Havelda, Z. (2019). Creating highly efficient resistance against wheat dwarf virus in barley by employing CRISPR/Cas9 system. Plant biotechnology journal, 17(6), 1004.

Koshino-Kimura, Y., Takenaka, K., Domoto, F., Ohashi, M., Miyazaki, T., Aoyama, Y. and Sera, T. (2009, September). Construction of plants resistant to TYLCV by using artificial zinc-finger proteins. In Nucleic Acids Symposium Series (Vol. 53, No. 1, pp. 281-282). Oxford University Press.

Lau, S. E., Mazumdar, P., Hee, T. W., Song, A. L. A., Othman, R. Y. and Harikrishna, J. A. (2014). Crude extracts of bacteriallyexpressed dsRNA protect orchid plants against Cymbidium mosaic virus during transplantation from in vitro culture. The Journal of Horticultural Science and Biotechnology, 89(5), 569-576.

Legg, J. P., Shirima, R., Tajebe, L. S., Guastella, D., Boniface, S., Jeremiah, S. and Rapisarda, C. (2014). Biology and management of Bemisia whitefly vectors of cassava virus pandemics in Africa. Pest management science, 70(10), 1446-1453.

Liang, Z., Chen, K., Zhang, Y., Liu, J., Yin, K., Qiu, J. L. and Gao, C. (2018). Genome editing of bread wheat using biolistic delivery of CRISPR/Cas9 in vitro transcripts or ribonucleoproteins. Nature protocols, 13(3), 413.

Liu, H., Soyars, C. L., Li, J., Fei, Q., He, G., Peterson, B. A. and Wang, X. (2018). CRISPR/Cas9-mediated resistance to cauliflower mosaic virus. Plant Direct, 2(3), e00047.

Mahas, A. and Mahfouz, M. (2018). Engineering virus resistance via CRISPR-Cas systems. Current opinion in virology, 32, 1-8.

Mandadi, K. K. and Scholthof, K. B. G. (2013). Plant immune responses against viruses: how does a virus cause disease?. The plant 
cell, 25(5), 1489-1505.

Mitter, N., Worrall, E. A., Robinson, K. E., Xu, Z. P. and Carroll, B. J. (2017). Induction of virus resistance by exogenous application of double-stranded RNA. Current opinion in virology, 26, 49-55.

Mori, T., Takenaka, K., Domoto, F., Aoyama, Y. and Sera, T. (2013). Inhibition of binding of tomato yellow leaf curl virus rep to its replication origin by artificial zinc-finger protein. Molecular biotechnology, 54(2), 198-203.

Namgial, T., Kaldis, A., Chakraborty, S. and Voloudakis, A. (2019). Topical application of double-stranded RNA molecules containing sequences of Tomato leaf curl virus and Cucumber mosaic virus confers protection against the cognate viruses. Physiological and Molecular Plant Pathology, 108, 101432.

Oerke, E. C. and Dehne, H. W. (2004). Safeguarding production-losses in major crops and the role of crop protection. Crop protection, 23(4), 275-285.

Ordiz, M. I., Magnenat, L., Barbas, C. F. and Beachy, R. N. (2010). Negative regulation of the RTBV promoter by designed zinc finger proteins. Plant molecular biology, 72(6), 621-630.

Price, A. A., Grakoui, A. and Weiss, D. S. (2016). Harnessing the prokaryotic adaptive immune system as a eukaryotic antiviral defense. Trends in microbiology, 24(4), 294-306.

Pyott, D. E., Sheehan, E. and Molnar, A. (2016). Engineering of CRISPR/Cas9-mediated potyvirus resistance in transgene-free Arabidopsis plants. Molecular plant pathology, 17(8), 1276-1288.

Regenmortel, M. H. and Mahy, B. W. (2009). Desk Encyclopedia of Plant and Fungal Virology.

Roossinck, M. J., Martin, D. P. and Roumagnac, P. (2015). Plant virus metagenomics: advances in virus discovery. Phytopathology, 105(6), 716-727.

Sahu, P. P. and Prasad, M. (2015). Application of molecular antiviral compounds: novel approach for durable resistance against geminiviruses. Molecular biology reports, 42(7), 1157-1162.
Sampson, T. R., Saroj, S. D., Llewellyn, A. C., Tzeng, Y. L. and Weiss, D. S. (2013). A CRISPR/Cas system mediates bacterial innate immune evasion and virulence. Nature, 497(7448), 254-257.

Schornack, S., Moscou, M. J., Ward, E. R. and Horvath, D. M. (2013). Engineering plant disease resistance based on TAL effectors. Annual review of phytopathology, 51, 383406.

Sera, T. (2005). Inhibition of virus DNA replication by artificial zinc finger proteins. Journal of virology, 79(4), 26142619.

Sharma, V. K., Basu, S. and Chakraborty, S. (2015). RNAi mediated broad-spectrum transgenic resistance in Nicotiana benthamiana to chilli-infecting begomoviruses. Plant cell reports, 34(8), 1389-1399.

Shepherd, D. N., Mangwende, T., Martin, D. P., Bezuidenhout, M., Thomson, J. A. and Rybicki, E. P. (2007). Inhibition of maize streak virus (MSV) replication by transient and transgenic expression of MSV replication-associated protein mutants. Journal of general virology, 88(1), 325-336.

Singh, A., Taneja, J., Dasgupta, I. and Mukherjee, S. K. (2015). Development of plants resistant to tomato geminiviruses using artificial trans-acting small interfering RNA. Molecular plant pathology, 16(7), 724-734.

Soler, N., Plomer, M., Fagoaga, C., Moreno, P., Navarro, L., Flores, R. and Peña, L. (2012). Transformation of Mexican lime with an intron-hairpin construct expressing untranslatable versions of the genes coding for the three silencing suppressors of Citrus tristeza virus confers complete resistance to the virus. Plant Biotechnology Journal, 10(5), 597-608.

Sovová, T., Kerins, G., Demnerová, K. and Ovesná, J. (2016). Genome editing with engineered nucleases in economically important animals and plants: state of the art in the research pipeline. Curr. Issues Mol. Biol, 21(21), 41-62.

Stella, S. and Montoya, G. (2016). The genome editing revolution: A CRISPR-Cas TALE 
off-target story. Inside the Cell, 1(1), 7-16.

Urnov, F. D., Rebar, E. J., Holmes, M. C., Zhang, H. S. and Gregory, P. D. (2010). Genome editing with engineered zinc finger nucleases. Nature Reviews Genetics, 11(9), 636-646.

Wang, X., Eggenberger, A. L., Nutter, F. W. and Hill, J. H. (2001). Pathogen-derived transgenic resistance to soybean mosaic virus in soybean. Molecular Breeding, 8(2), 119-127.

Whitfield, A. E., Falk, B. W. and Rotenberg, D. (2015). Insect vector-mediated transmission of plant viruses. Virology, 479, 278-289.

Whitham, S. A. and Hajimorad, M. R. (2016). Plant genetic resistance to viruses. In Current Research Topics in Plant Virology (pp. 87-111). Springer, Cham.

Worrall, E. A., Bravo-Cazar, A., Nilon, A. T., Fletcher, S. J., Robinson, K. E., Carr, J. P. and Mitter, N. (2019). Exogenous application of RNAi-inducing doublestranded RNA inhibits aphid-mediated transmission of a plant virus. Frontiers in plant science, 10, 265.

Ye, C. and Li, H. (2010). 20 Years of transgenic research in China for resistance to Papaya ringspot virus. Transgenic Plant J., 4, 5863.

Yin, K. and Qiu, J. L. (2019). Genome editing for plant disease resistance: applications and perspectives. Philosophical Transactions of the Royal Society B, 374(1767), 20180322.

Zaidi, S. S. E. A., Tashkandi, M. and Mahfouz,
M. M. (2017). Engineering molecular immunity against plant viruses. In Progress in molecular biology and translational science (Vol. 149, pp. 167186). Academic Press.

Zaidi, S. S. E. A., Tashkandi, M., Mansoor, S. and Mahfouz, M. M. (2016). Engineering plant immunity: using CRISPR/Cas9 to generate virus resistance. Frontiers in plant science, 7, 1673.

Zhan, X., Zhang, F., Zhong, Z., Chen, R., Wang, Y., Chang, L. and Zhang, J. (2019). Generation of virus-resistant potato plants by RNA genome targeting. Plant biotechnology journal, 17(9), 1814-1822.

Zhang, T., Zhao, Y., Ye, J., Cao, X., Xu, C., Chen, B. and Zhou, G. (2019). Establishing CRISPR/Cas13a immune system conferring RNA virus resistance in both dicot and monocot plants. Plant biotechnology journal, 17(7), 1185.

Zhang, T., Zheng, Q., Yi, X., An, H., Zhao, Y., Ma, S. and Zhou, G. (2018). Establishing RNA virus resistance in plants by harnessing CRISPR immune system. Plant biotechnology journal, 16(8), 14151423.

Zhang, Z. Y., Wang, Y. G., Shen, X. J., Li, L., Zhou, S. F., Li, W. C. and Fu, F. L. (2013). RNA interference-mediated resistance to maize dwarf mosaic virus. Plant Cell, Tissue and Organ Culture (PCTOC), 113(3), 571-578.

\section{How to cite this article:}

Biswajit Lenka, Satya Narayan Satapathy and Manoranjan Senapati. 2020. Engineering Plant Virus Resistance: Gene Silencing to Genome Editing. Int.J.Curr.Microbiol.App.Sci. 9(10): 3086-3096. doi: https://doi.org/10.20546/ijcmas.2020.910.371 